\title{
Pemodelan dan Pengendalian Motor Listrik U.S. Electric Motor Type Dripproof 30 HP/240 V/108 A
}

\author{
Irman Amri \\ Fakultas Teknik Universitas Al-Amin Muhammadiyah Sorong
}

\begin{abstract}
ABSTRAK
Starting secara langsung (DOL) yang dilakukan pada sebuah Motor DC akan menyebabkan kerusakan pada motor tersebut, karena arus starting yang sangat besar. Pengontrolan terhadap tegangan Jangkar ( Ea) dan Tahanan Seri(Rs) dengan Model Pengontrolan Daur Terbuka akan memberikan pengurangan arus starting dan stopping yang cukup signifikan. Begitupula dengan Pengontrolan dengan Daur Tertutup selain mengurangi arus starting dan stopping juga akan menstabilkan kecepatan motor ketika bebannya berubah ubah. Unjuk kerja dari motor DC Type Dripproof $30 \mathrm{HP}, 240 \mathrm{~V}, 108 \mathrm{~A}$, dengan menggunakan program Simulink menunjukkan Arus Starting DOL yang sebelumnya 1370 A turun menjadi 153,4 A pada pengaturan Tegangan Jangkar(Ea) dan 182,96 A pada pengaturan tahanan seri (Rs), sedangkan kecepatan pada DOL sebear 2991 rpm, turun menjadi 2515,3 rpm pada pengaturan tegangan jangkar dan 2507 rpm pada pengaturan tahanan seri.
\end{abstract}

Kata kunci : model motor,pengontrolan, simulink, Ea, Rs

\section{PENDAHULUAN}

Motor DC telah digunakan di dalam industri selama bertahun-tahun. Motor DC dapat digunakan untuk conveyor, elevator, extruders, peralatan bawah air, material handling, kertas, plastik, karet, dan peralatan tekstil sebagai beberapa contoh.

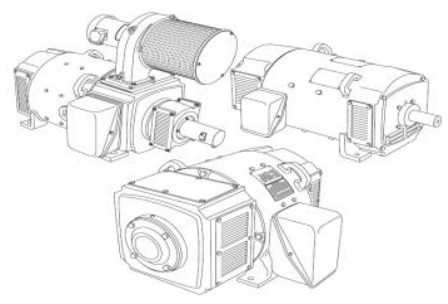

Gambar 1. Beberapa motor DC
Beberapa hal penting yang patut diketahui sehubungan dengan operasi motor DC, antara lain :

Gaya , Dalam terminologi umum, suatu gaya adalah tarikan atau dorongan. Gaya dapat disebabkan oleh elektromagnet, gravitasi, atau kombinasi dari gaya-gaya fisik lain. Gaya mempunyai satuan Newton $(\mathrm{N})$.

Torsi adalah gaya puntir yang dapat menyebabkan suatu objek berputar. Sebagai contoh, suatu gaya yang diterapkan terhadap ujung pengungkit menyebabkan efek puntir atau torsi pada titik porosnya.

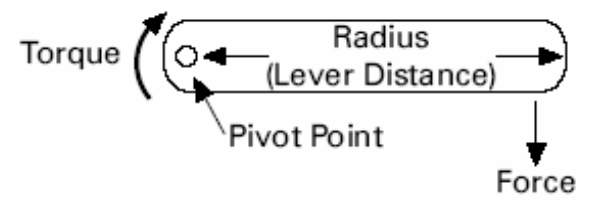




\section{Gambar 2. Torsi}

Torsi ( $\mathrm{T}$ ) dihasilkan dari perkalian hasil gaya dan jari-jari (panjang lenganpengungkit) dan diberi satuan $\mathrm{N}-\mathrm{m}$.

Inersia , Sistem mekanis mengikuti hukum kelembaman (inersia). Hukum kelembaman menyatakan bahwa suatu objek akan cenderung untuk tetap pada kondis semula (dalam keadaan diam/istirahat atau bergerak) kecuali mendapatkan gaya luar.

Gesekan/Friksi, Akibat gesekan (friction) yang menyerap energi dari sistem mekanis, maka diperlukan gaya yang terus menerus untuk menjaga agar objek tetap bergerak. Hukum kelembaman masih berlaku dalam hal ini, dimana gaya yang diperlukan hanya untuk mengganti energi yang hilang oleh gesekan.

Kecepatan ,Suatu objek yang bergerak akan menempuh suatu jarak tertentu dalam waktu yang ditentukan. Kecepatan adalah perbandingan jarak tempuh dan waktu yang digunakan untuk menempuhnya.

Kecepatan pada Objek Berputar, Kecepatan juga diterapkan untuk benda yang berputar, seperti ban mobil atau as motor. Dalam hal ini dikenal dengan kecepatan putar. Kecepatan dari benda yang berputar adalah suatu ukuran berapa lama suatu titik pada benda yang berputar dapat menyelesaikan satu perputaran penuh. Kecepatan putar suatu benda umumnya dinyatakan dalam putaran per menit (RPM-revolution per minute). Suatu benda yang berhasil membuat sepuluh putaran penuh dalam dalam satu menit mempunyai kecepatan 10 RPM.

\section{Konstruksi Motor DC}

Motor DC tersusun dari beberapa komponen utama berikut: Rangka -Frame, As -Shaft ,Bearings Kumparan Medan Utama-Main field
Windings (Stator) Jangkar, rotor Armature ,Commutator ,Sikat-Brush Assembly

Dari komponen-komponen di atas, diperlukan pemahaman yang baik tentang karakter listrik dari kumparan medan utama yang dikenal sebagai stator, dan kumparan jangkar, yang dikenal sebagai rotor.

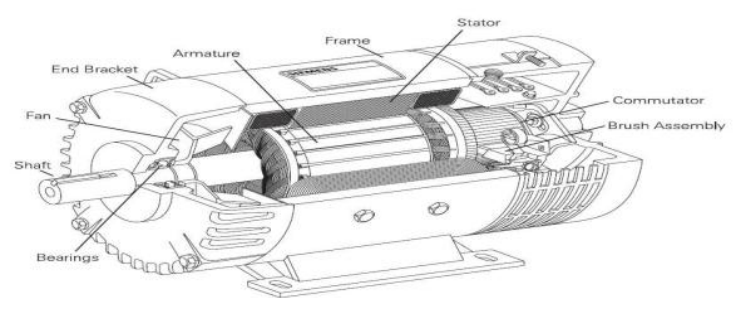

Gambar 3. Konstruksi Motor DC

\section{I.1. Prinsip Kerja Motor DC}

Sebagaiman telah disampaikan sebelumnya bahwa terdapat dua elemen listrik dari motor DC, bagian stator (kumparan medan utama) dan rotor (kumparan jangkar). Kumparan jangkar mengalirkan arus yang berasal dari komutator. Tegangan DC dialirkan ke kumparan jangkar melalui karbon yang menempel komutator. Meskipun pada motor DC kecil, magnet permanen dapat digunakan sebagai stator. Tetapi, pada motor yang besar, yang biasa digunakan di industri menggunakan elektomagnet sebagai stator. Pada saat tegangan dialirkan ke kumparan medan di stator dengan kutub utara dan selatan buatan (elekromagnet), akan dihasilkan medan magnet statis (bukan medan magnet putar - akan dibahas pada motor AC). Untuk menjelaskannya, stator akan dianggap sebagai magnet permanen.

Motor DC berputar sebagai akibat adanya dua medan magnet yang saling berinteraksi satu sama lain. Medan pertama adalah medan magnet utama yang berada pada kumparan stator, dan medan 
kedua adalah medan magnet yang berada di jangkar.

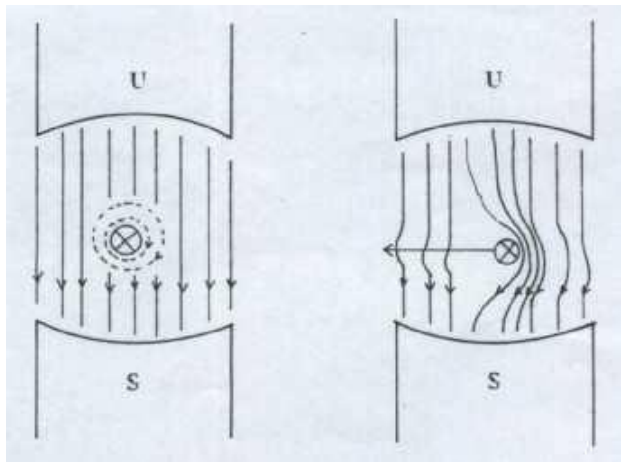

Gambar 4.

GGL Lawan (B/CEMF -Back/Counter Electromotive Force-)

Saat motor telah bergerak/ berputar, ini berarti jangkar berputar dalam medan magnet stator, sesuai prinsip Faraday maka padanya (jangkar) akan timbul tegangan induksi. Tegangan yang dihasilkan oleh jangkar ini dikenal sebagai GGL lawan. GGL Lawan akan mengurangi tegangan dari jangkar.

\section{I.2. Tipe - Tipe Dari Motor Dc}

Medan magnet dari motor DC bisa terbuat dari magnet permanen, atau elektromagnet yang tersambung dalam rangkaian seri, shunt, atau compound.

\section{Motor Magnet Permanen}

Motor magnet permanen menggunakan magnet permanen untuk menyuplai fluks magnet. Motor DC jenis ini, memiliki torsi start dan regulasi kecepatan yang bagus. Kekurangan dari motor DC jenis ini adalah keterbatasan dari besar beban yang dapat ditarik. Motor ini tersedia pada alatalat dengan HP rendah.

\section{Motor Seri}

Pada motor DC seri, kumparan medan disambungkan secara seri dengan rotor. Kumparan bertipe Wound dengan diameter besar dipasangkan, hal ini dilakukan karena harus membawa arus rotor yang penuh (secara keseluruhan, termasuk arus beban).

Karakteristik dari motor DC seri, motor jenis menghasilkan torsi awal yang besar. Tetapi, motor jenis ini mempunyai variasi kecepatan yang lebar antara saat tanpa beban dan saat beban penuh. Motor seri tidak sesuai jika digunakan untuk membawa beban dengan kecepatan konstan, motor ini diperlukan untuk membawa muatan yang bervariasi. Sebagai tambahan, motor jenis ini mempunyai karakteristik bahwa saat tanpa beban, kecepatan akan terus naik sampai batas yang dapat menimbulkan kerusakan terhadap dirinya. Untuk menghindari kecepatan yang berlebih tersebut motor ini harus selalu disambungkan dengan beban.

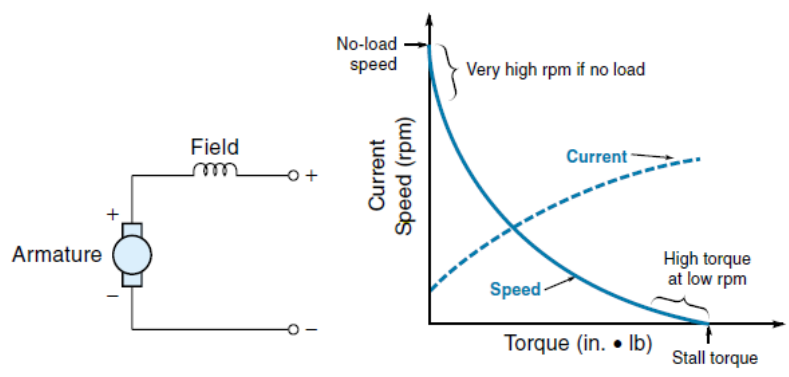

Gambar 5. Rangkaian motor seri dan karakteristik arus dan kecepatannya

\section{Motors Shunt}

Pada motor shunt, rangkaian kumparan medan terhubung pararel dengan kumparan rotor. Motor DC shunt mempunyai karakteristi regulasi tegangan yang baik. Kumparan medan dapat disuplai dari sumber tegangan tersendiri, maupun disambungkan dengan kumparan jangkar, keuntungannya adalah memungkinkan dikendalikannya kumparan medan dan kumparan jangkar secara independen. 

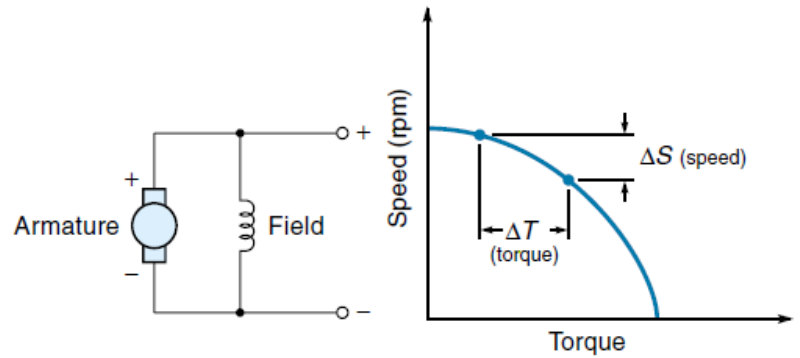

Gambar 6. Rangkaian motor shunt dan karakteristik kecepatannya

\section{Motor DC Compound}

Motor compound mempunyai dua kumparan medan. Mereka adalah kumparan medan seri dan kumparan medan shunt. Kumparan medan seri memungkinkan didapatkannya torsi awal yang lebih baik dan kumparan medan shunt memungkinkan didapatkannya regulasi kecepatan yang lebih baik. Tetapi medan seri dapat menyebabkan masalah untuk penerapan yang membutuhkan variasi kecepatan.
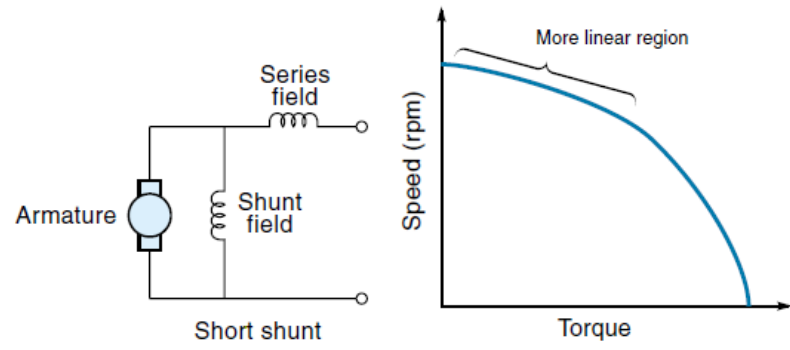

Gambar 7 . Rangkaian motor compound dan karakteristik kecepatannya

Pada starting/penghasutan motor DC, arus starting biasanya sangat besar, kondisi ini harus diperbaiki atau diminimalkan mengingat arus starting yang besar tersebut sangat berpotensi untuk merusak motor yang ada. Demikian pula dengan setiap kondisi transient, kondisi arus yang besar hrus diminimalkan. Untuk menjaga kondisi motor agar tetap dalam kondisi normal.

\section{PEMODELAN MOTOR DC TERKENDALI JANGKAR}

\section{Model Fisik}

Model fisik dari sebuah motor DC dapat digambarkan sebagai berikut:

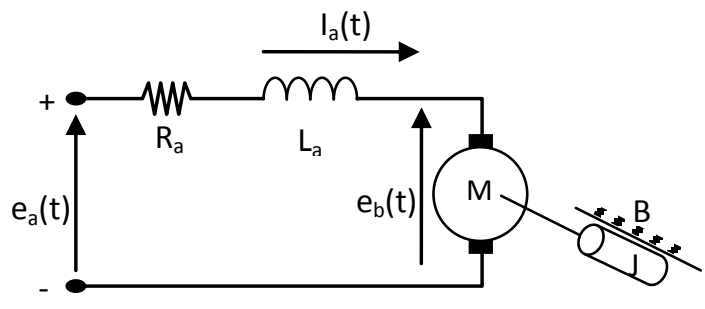

Gambar 8. Model Fisik Motor

keterangan:

$$
\begin{array}{ll}
\mathrm{R}_{\mathrm{a}} & =\text { tahanan jangkar } \\
\mathrm{L}_{\mathrm{a}} & =\text { induktansi jangkar } \\
\mathrm{e}_{\mathrm{a}}(\mathrm{t}) & =\text { tegangan jangkar } \\
\mathrm{e}_{\mathrm{b}}(\mathrm{t}) & =\text { back emf } \\
\mathrm{I}_{\mathrm{a}}(\mathrm{t}) & =\text { arus jangkar } \\
\mathrm{M} & =\text { motor } \\
\mathrm{J} & =\text { momen inersia } \\
\mathrm{B} & =\text { beban (friction) }
\end{array}
$$

Pada makalah ini, digunakan Motor DC Terkendali Jangkar Merk U.S. Electrical Motors Type Dripproof dengan spesifikasi sebagai berikut:

\begin{tabular}{|c|l|c|c|}
\hline No & Spesifikasi Data & Simbol & Satuan \\
\hline 1 & Daya Mekanik & $\mathrm{P}_{\text {mek }}$ & $30 \mathrm{HP}$ \\
2 & Kecepatan Nominal & $\omega_{\text {nom }}$ & $2500 \mathrm{rpm}$ \\
3 & Tegangan Jangkar & $\mathrm{E}_{\mathrm{a} \text { nom }}$ & $240 \mathrm{Volt}$ \\
& Nominal & & \\
4 & Arus Jangkar Nominal & $\mathrm{I}_{\mathrm{a} \text { nom }}$ & $108 \mathrm{~A}$ \\
5 & Resistansi Jangkar & $\mathrm{R}_{\mathrm{a}}$ & $0,088 \Omega$ \\
6 & Induktansi Jangkar & $\mathrm{L}_{\mathrm{a}}$ & $0,002 \mathrm{H}$ \\
7 & Momen Inersia & $\mathrm{J}$ & $3,40{\mathrm{~b} . \mathrm{ft}^{2}}^{2}$ \\
\hline
\end{tabular}

\section{Model Matematik}

Dari model fisik motor DC di atas, dan dengan menggunakan hukum-hukum listrik seperti 
hukum $\Omega$, tegangan, dan lain-lain, maka diperoleh persamaan (model) matematik sebagai berikut:

\section{Bagian elektrik:}

$e_{a}(t)-e_{b}(t)=L_{a} \frac{d i_{a}(t)}{d t}+R_{a} i_{a}(t) \ldots$

Bagian mekanik:

$T(t)=J \frac{d \omega(t)}{d t}+B \omega(t)$

\section{Sifat motor:}

$T(t)=K_{m} i_{a}(t)$

Sifat generator:

$e_{b}(t)=K_{b} \omega(t)$

\section{Model Nisbah Alih}

Dari persamaan (1) di atas, dengan transformasi laplace diperoleh:

$\frac{I_{a}(s)}{E_{a}(s)-E_{b}(s)}=\frac{1}{L_{a} s+R_{a}}$

Sedangkan dari persamaan (2) diperoleh:

$\frac{\omega(s)}{T(s)}=\frac{1}{J s+B}$

Dengan menggunakan hubungan-hubungan di atas, maka keseluruhan persamaan matematis Motor DC di atas dapat digambarkan dalam model nisbah alih dengan menggunakan bagan kotak seperti berikut ini:
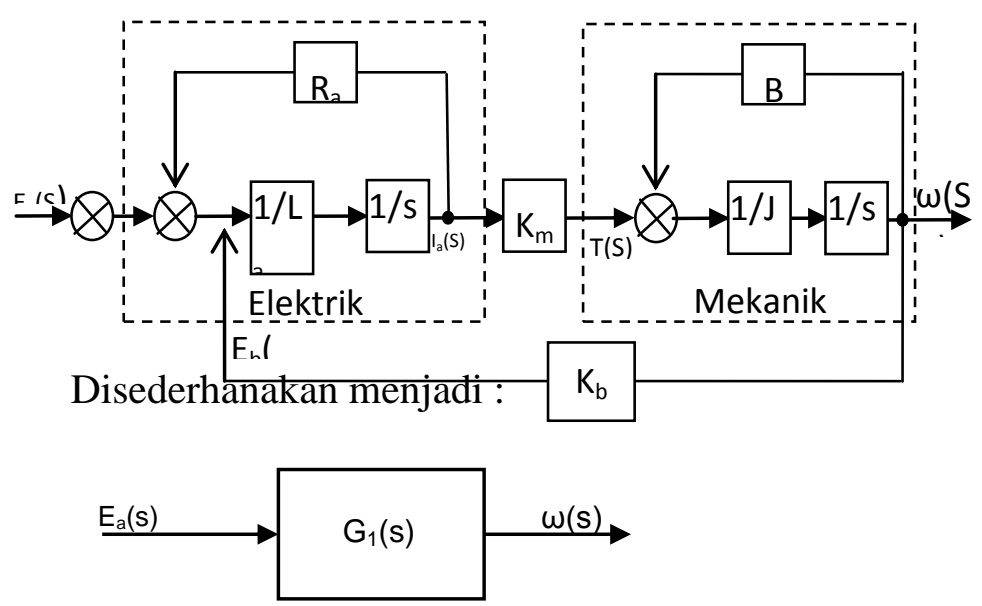

dimana:

$$
\begin{aligned}
G(s) & =\frac{\frac{K_{m}}{\left(L_{a} s+R_{a}\right)(J s+B)}}{1+\frac{K_{m} \cdot B}{\left(L_{a} s+R_{a}\right)(J s+B)}} \\
& =\frac{K_{m}}{L_{a} J s^{2}+\left(B L_{a}+R_{a} J\right) s+R_{a} B+K_{m} K_{b}} \\
& =\frac{K_{m} / L_{a} J}{s^{2}+\frac{B L_{a}+R_{a} J}{L_{a} J} s+\frac{R_{a} B+K_{m} K_{b}}{L_{a} J}} \\
& \cong \frac{K_{0}}{s^{2}+2 \xi \omega_{n} s+\omega_{n}{ }^{2}}
\end{aligned}
$$

Jadi motor DC terkendali jangkar ini pada keadaan transient akan mengikuti karakteristik suatu sistem orde kedua (second order systems) dengan:

$K_{0}=\frac{K_{m}}{L_{a} J} \quad 2 \xi \omega_{n}=\frac{B L_{a}+R_{a} J}{L_{a} J} \quad \omega_{n}{ }^{2}=\frac{B R_{a}+K_{m} K_{b}}{L_{a} J}$

$K_{0}=$ konstanta

$\omega_{n}=$ frekuensi alamiah tak teredam (undamped natural frequency)

$\xi=$ nisbah redaman (damping ratio)

\section{PENGENDALIAN MOTOR DC DAUR TERBUKA}

Pengendalian mempunyai kata dasar kendali yang berarti suatu tindakan yang mengarahkan suatu proses untuk menghasilkan suatu produk dengan kualitas yang diharapkan. Pengendalian motor bisa dilakukan pada pada saat starting dan stoping sebuah motor DC, untuk mengurangi arus transient pada saat start dan stop ( biasanya daur terbuka ), serta mungkin dilakukan dalam kondisi motor bekerja untuk menjaga kestabilan kerja motor khusus untuk kualitas kerja motor yang diinginkan tetap dan sangat baik(biasanya daur tertutup).

Sistem Kendali Daur terbuka, keluaranya tidak mempengaruhi input. Atau dengan kata lain sistem kendali daur terbuka keluarannya (output) tidak dapat digunakan sebagai perbandingan umpan balik dengan inputnya. Akibatnya 
ketetapan dari sistem tergantung dari kalibrasi. Pada umumnya, sistem kendali daur terbuka tidak tahan terhadap gangguan luar. System kendali Daur Terbuka secara umum digambarkan sebagai berikut :

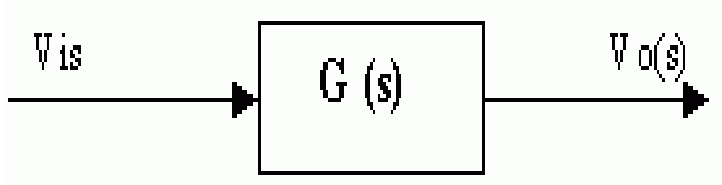

\section{a. Starting Motor DC dengan Pengaturan Tegangan Jangkar $\mathbf{E}_{\mathbf{a}}$}

Untuk men-start motor DC, salah satu pengaturan yang dapat dilakukan adalah dengan mengatur tegangan jangkar agar tidak langsung mencapai tegangan nominalnya. Dengan cara tersebut, diharapkan lonjakan arus yang sangat besar yang terjadi pada starting DOL (Direct On Line) dapat diatasi sehingga tidak menyebabkan kerusakan pada motor DC tersebut.

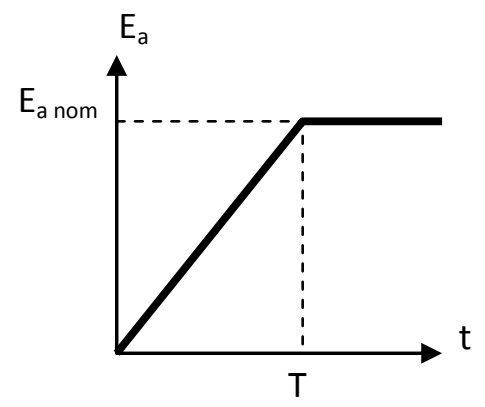

Pengaturan tegangan yang dimaksud adalah dengan menaikkan tegangan jangkar secara perlahan dari 0 sampai $\mathrm{E}_{\mathrm{a} \text { nom }}$ dalam waktu $\mathrm{T}$.

Model rangkaian pengganti Motor DC kendali jangkar yang disimulasikan sebagai berikut :

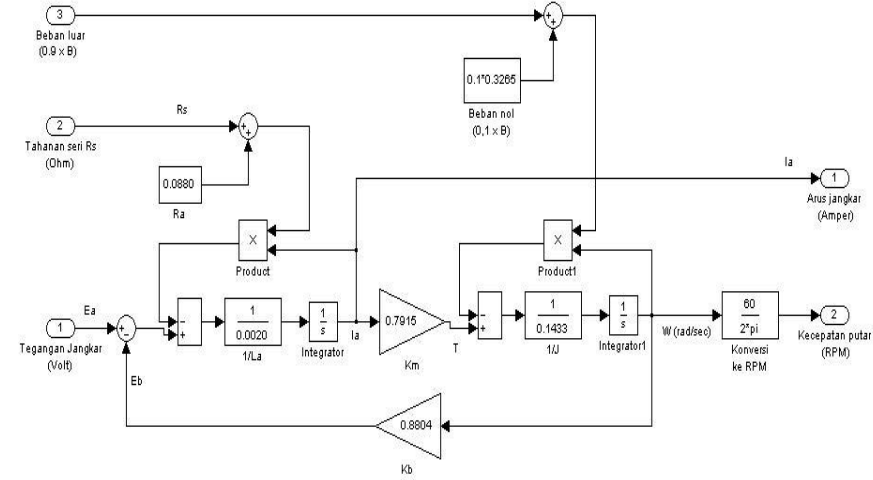

Model motor DC diatas akan dimasukkan kedalam model sistem dengan pengaturan tegangan yang akan disimulasikan, sebagai berikut:

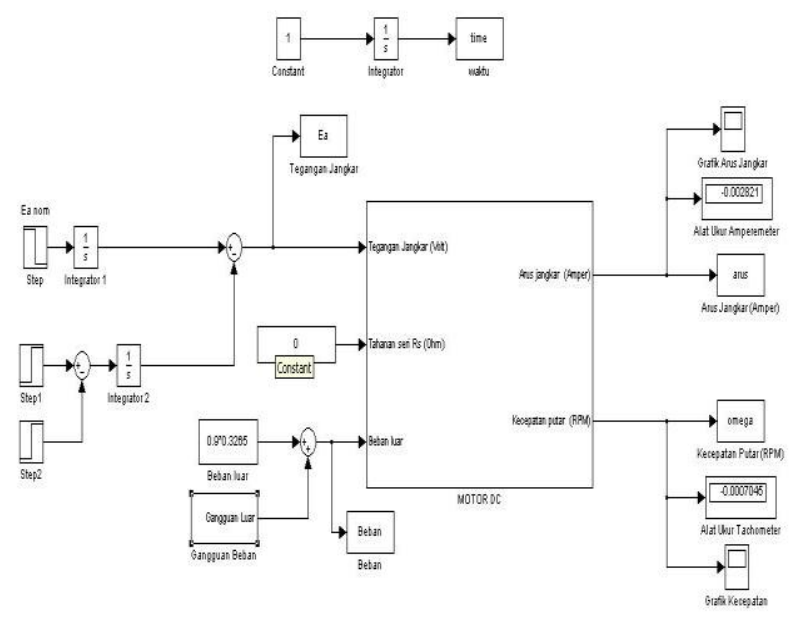

Pada simulasi diatas diasumsikan juga bahwa ketika kondisi Tegangan Jangkar telah berada pada tegangan nominalnya, dicoba diberikan gangguan untuk melihat respon motor ketika gangguan diberikan, gangguan tersebut dilakukan dengan melakukan perubahan beban selama beberapa saat , adapun model gangguannya disimulasikan sebagai : 


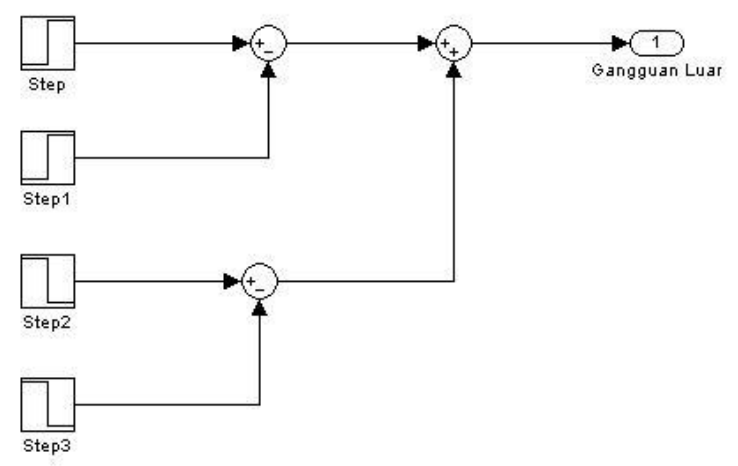

Hasil simulasinya :

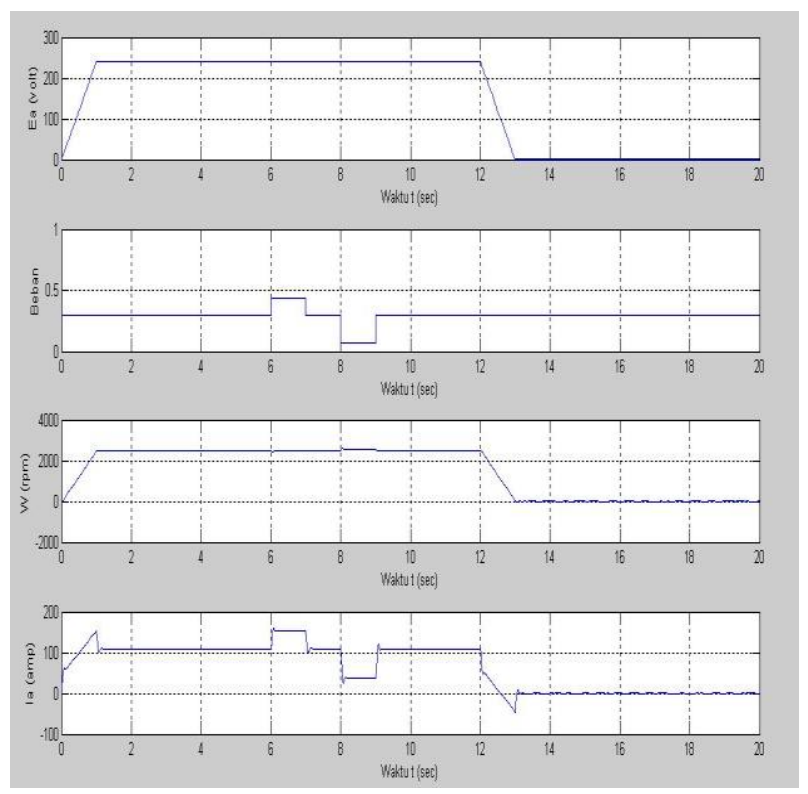

Dari grafik terlihat bahwa pengaturan Tegangan Jangkar yang dilakukan secara perlahan akan menurunkan arus nominal yang pada saat di start langsung ( DOL ) cukup besar yaitu hampir 14 kali dari arus nominal menjadi hanya sekitar 1,42 kali arus nominal ( 153,4 A)

Sementara putaran nominal yang sebelumnya pada saat starting DOL yang nilainya naik lebih dari 3 kali lipat, dengan pengaturan tegangan ini, maka putaran motor naik secara perlahan sampai pada putaran nominal, dengan hampir tidak ada lonjakan putaran (lonjakan relatif sangat kecil) yaitu 1,00612 kali.(2515,3 rpm)
Dalam Kondisi Tegangan Jangkar, arus jangkar dan Kecepatan Putaran telah nominal, maka dicoba untuk dilakukan perubahan pembebanan, yaitu dengan menaikkan beban motor menjadi 0,5 kali lipat dari beban luarnya, pada detik $\mathrm{t}=6$, sampai detik ke $t=7$, terlihat bahwa perubahan beban tersebut, menyebabkan putaran motor menjadi lebih kecil dari putaran nominalnya, dan arus jangkar menjadi naik dari nilai arus nominalnya

Pada saat diberikan gangguan dengan menurunkan beban motor menjadi 0,75 kali lipat dari beban luar, pada detik $\mathrm{t}=8$, sampai detik ke $\mathrm{t}=9$, terlihat bahwa perubahan beban tersebut menyebabkan putaran motor menjadi lebih besar dari putaran nominalnya, dan arus jangkar menjadi turun dari nilai arus nominalnya

\section{a. Starting Motor DC dengan Pengaturan Tahanan Seri $\left(\mathbf{R}_{\mathrm{s}}\right)$}

Untuk men-start motor DC, selain dengan mengatur tegangan jangkar untuk menghindari lonjakan arus yang besar , juga dapat dilakukan dengan melakukan pengaturan tahanan seri $\left(\mathrm{R}_{\mathrm{s}}\right)$

Pengaturan $R_{\text {seri }}$ dilakukan dengan mempertah ankan nilai

$\mathrm{R}_{\text {seri }}$ tersebut selama periode waktu

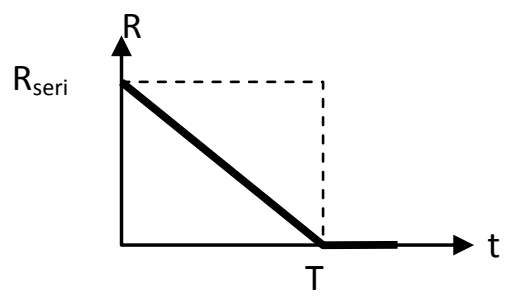
tertentu (misalnya 0,1 detik), kemudian menurunkannya secara perlahan sampai mencapai 0 dalam waktu T.

Dengan model rangkaian simulasi motor yang sama seperti pada pengaturan tegangan jangkar maka Model Sistem pengaturan tahanan seri dengan simulink digambarkan sebagai berikut : 


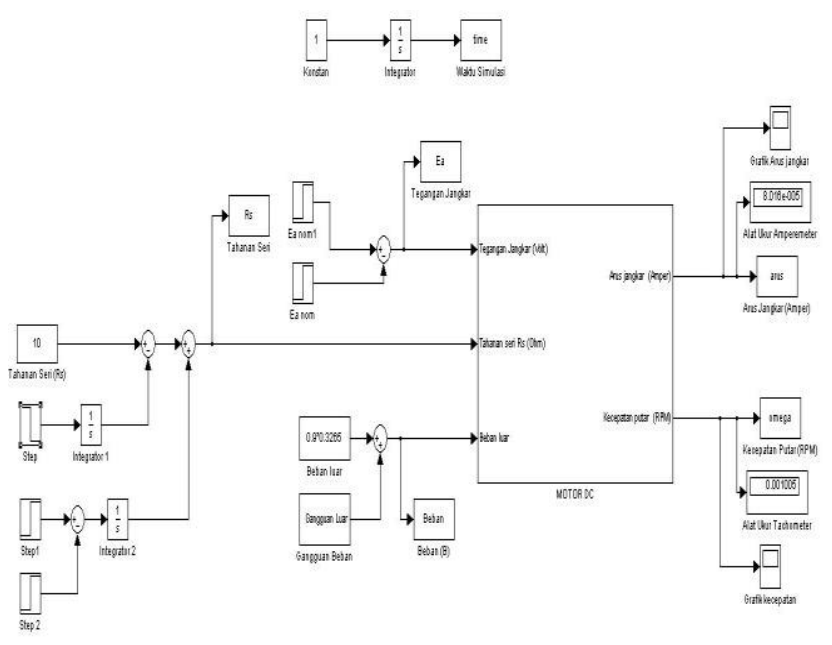

Diperoleh Hasil Simulasi sebagai berikut :

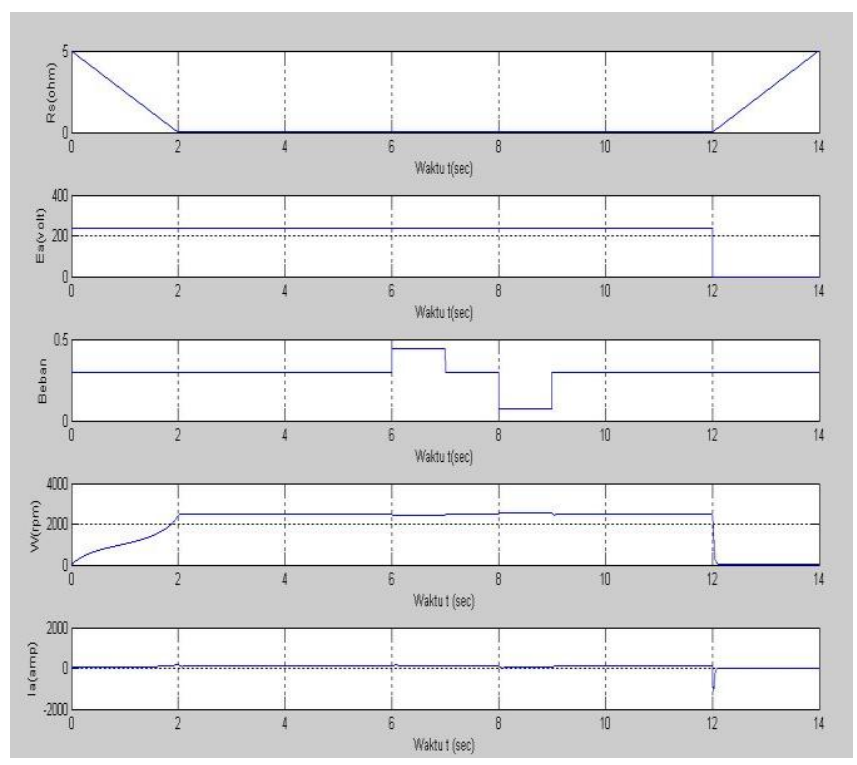

Dari grafik terlihat bahwa pengaturan Tahanan Seri yang dilakukan secara perlahan akan menurunkan arus nominal yang pada saat di start langsung ( DOL ) cukup besar yaitu hampir 14 kali dari arus nominal Starting DOL menjadi hanya sekitar 1,69 kali arus nominal (182,96 A)

Sementara putaran nominal yang sebelumnya pada saat starting DOL yang nilainya naik lebih dari 3 kali lipat, dengan pengaturan tahanan ini, maka putaran motor naik secara perlahan sampai pada putaran nominal, dengan hampir tidak ada lonjakan putaran (lonjakan relatif sangat kecil) sebesar $2501 \mathrm{rpm}$.

Sementara dalam Kondisi Tegangan Jangkar, arus jangkar dan Kecepatan Putaran telah nominal, maka dicoba untuk dilakukan perubahan pembebanan, yaitu dengan menaikkan beban motor menjadi 0,5 kali lipat dari beban luarnya, pada detik $\mathrm{t}=6$, sampai detik ke $\mathrm{t}=7$, terlihat bahwa perubahan beban tersebut, menyebabkan putaran motor menjadi lebih kecil dari putaran nominalnya, dan arus jangkar menjadi naik dari nilai arus nominalnya.

Dari Grafik terlihat juga bahwa ketika diberi gangguan dengan menaikkan beban sebesar 0,5 kali lipat dari beban luar, maka terjadi lonjakan (overshoot) hampir 1,49 kali lipat dari arus nominalnya pada saat beban berubah $(161,5 \mathrm{~A})$ dan selama gangguan, arus tersebut stabil pada 152,82 A . Sementara pada kondisi gangguan tersebut Putaran mengalami penurunan sampai sekitar 2422,8 rpm pada awal perubahan beban dan selama gangguan tersebut putaran tetap pada pada 2439 rpm. Ketika gangguan tersebut dihilangkan pada $\mathrm{t}=7$, maka Arus jangkar dan putaran kembali pada kondisi nominal mesin , dengan terjadi lonjakan pada saat perubahan dari posisi gangguan ke kondisi normal.

Pada saat diberikan gangguan dengan menurunkan beban motor menjadi 0,75 kali lipat dari beban luar, pada detik $\mathrm{t}=8$, sampai detik ke $\mathrm{t}=9$, terlihat bahwa perubahan beban tersebut menyebabkan putaran motor menjadi lebih besar dari putaran nominalnya yaitu sekitar 2578,1 rpm pada awal perubahan beban dan selama gangguan tersebut putaran tetap pada pada $2551 \mathrm{rpm}$. Dari Grafik juga terlihat bahwa ketika diberi gangguan dengan menurunkan beban sebesar 0,75 kali lipat dari beban luar, maka terjadi penurunan arus jangkar secara signifikan hampir 5 kali lebih kecil dari arus nominalnya (21,192 A) pada saat beban berubah dan selama gangguan, arus tersebut stabil pada sekitar $36 \mathrm{~A}$. 


\section{IV.PENGENDALIAN MOTOR DC DAUR TERTUTUP.}

Sistem kendali daur tertutup seringkali disebut sistem kendali umpan balik. Pada sistem kendali daur tertutup, sinyal kesalahan yang bekerja, yaitu perbedaan antara sinyal input dan sinyal umpan balik diinputkan kekontroller sedemikian rupa untuk mengurangi kesalahan dan membawa keluaran sistem kenilai yang dikehendaki. Pada umumnya sistem kendali daur tertutup tahan terhadap gangguan dari luar.

Secara umum gambar Sistem Kendali Daur Tertutup adalah sebagai berikut :

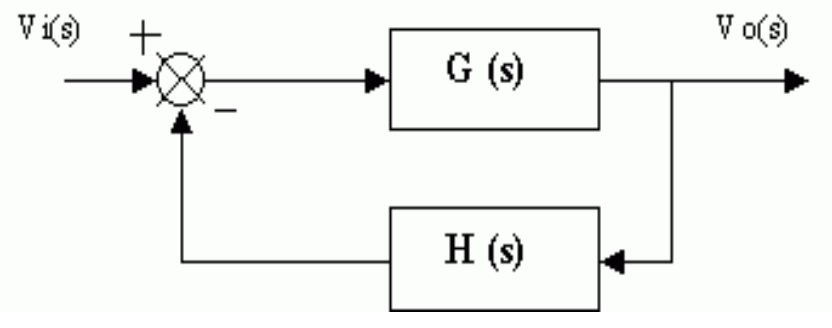

Model Sistem Motor DC Kendali Jangkar Daur tertutup disimulasikan sebagai berikut :

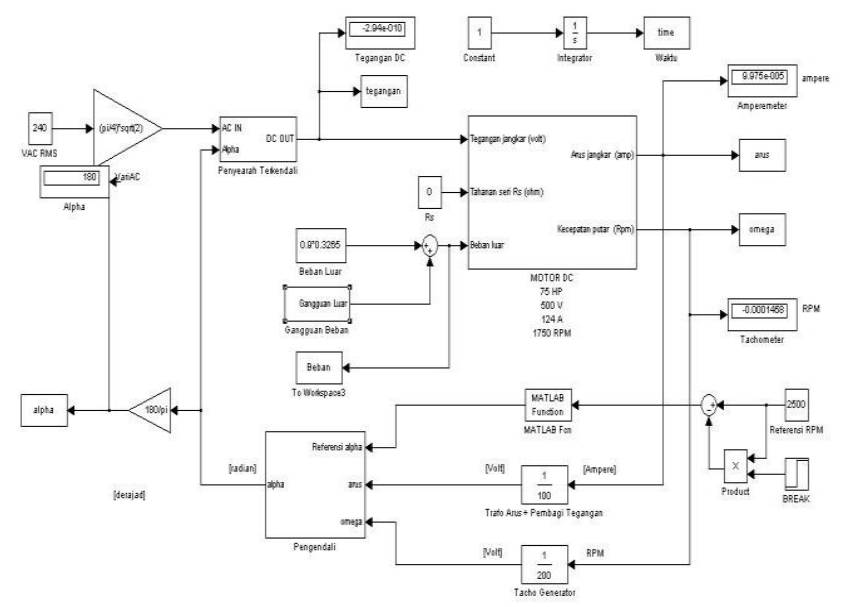

Simulasi ini dilakukan dengan membandingkan antara kecepatan motor DC setiap saat yang diterima oleh sebuah sensor kecepatan (tachogenerator) dengan kecepatan referensi motor (Kecepatan Nominalnya) , Prosesnya kemudian melalui sebuah pengendali, arus jangkar motor, kecepatan motor dan referensi dirubah dalam sebuah sudut alpha yang oleh sebuah penyearah terkendali kemuadian mengatur tegangan jangkar dan arus jangkar untuk menjaga agar kecepatan putaran motor selalu konstan. Dengan demikian setiap perubahan beban yang terjadi yang seharusnya akan merubah kecepatan putar motor diharapkan tidak terjadi atau minimal perubahannya relative sangat kecil (kecepatan tetap pada kecepatan nominalnya)

Ketika disimulasikan diperoleh hasil simulasi sebagai berikut :

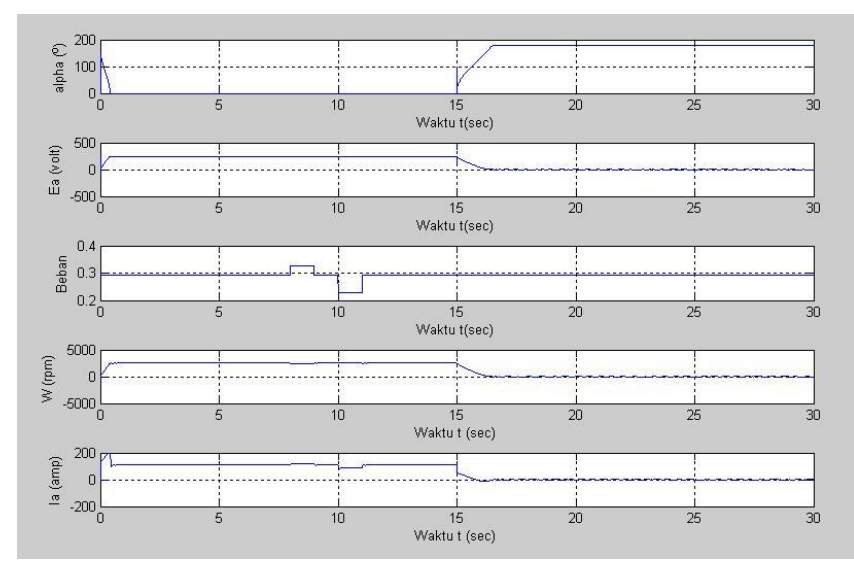

Hasil Simulasi menunjukkan bahwa Tahanan Seri yang dilakukan secara perlahan akan menurunkan arus nominal yang pada saat di start langsung (DOL) cukup besar yaitu hampir 14 kali dari arus nominal Starting DOL menjadi hanya sekitar 1,7 kali arus nominal (194,42 A) nilai ini memang sedikit lebih besar dari pengaturan dengan daur terbuka namun kenaikan yang terjadi tidak Tajam akan tetapi lebih landai.

Untuk putaran nominal yang sebelumnya pada saat starting DOL yang nilainya naik lebih dari 3 kali lipat, dengan pengaturan daur tertutup ini , maka putaran motor naik secara perlahan sampai pada putaran nominal, dengan hampir tidak ada lonjakan putaran (lonjakan relatif sangat kecil, hanya sampai $2500,9 \mathrm{rpm}$ ) 
Sementara dalam Kondisi Tegangan Jangkar, arus jangkar dan Kecepatan Putaran telah nominal , maka dicoba untuk dilakukan perubahan pembebanan, yaitu dengan menaikkan beban motor menjadi 0,1 kali lipat dari beban luarnya , pada detik $\mathrm{t}=8$, sampai detik ke $\mathrm{t}=9$, terlihat bahwa perubahan beban tersebut, menyebabkan putaran motor menjadi lebih kecil dari putaran nominalnya, dan arus jangkar menjadi naik dari nilai arus nominalnya. Perubahan beban itu , maka terjadi lonjakan (overshoot) hanya 0,11 kali lipat dari arus nominalnya pada saat beban berubah (120,35 A) dan selama gangguan, arus tersebut stabil pada 118,33 A . Sementara pada kondisi gangguan tersebut Putaran mengalami penurunan sampai sekitar 2486,2 rpm pada awal perubahan beban dan selama gangguan tersebut putaran tetap pada pada 2490,2 rpm. Ketika gangguan tersebut dihilangkan pada $\mathrm{t}=9$, maka Arus jangkar dan putaran kembali pada kondisi nominal mesin , dengan terjadi lonjakan pada saat perubahan dari posisi gangguan ke kondisi normal.

Pada saat diberikan gangguan dengan menurunkan beban motor menjadi 0,2 kali lipat dari beban luar, pada detik $\mathrm{t}=9$, sampai detik ke $\mathrm{t}=10$, terlihat bahwa perubahan beban tersebut menyebabkan putaran motor menjadi lebih besar dari putaran nominalnya yaitu sekitar $2528 \mathrm{rpm}$ pada awal perubahan beban dan selama gangguan tersebut putaran tetap pada pada $2520 \mathrm{rpm}$, sementara kondisi maka terjadi penurunan arus jangkar secara signifikan hampir 0,167 kali lebih kecil dari arus nominalnya $(82,924$ A) pada saat beban berubah dan selama gangguan, arus tersebut stabil pada sekitar 87,088 A.

Perubahan Arus jangkar dan kecepatan putaran dengan Pengontrolan daur tertutup ini memberikan kecenderungan yang lebih konstan pada kondisi transient, perubahan yang terjadi relative sangat kecil. Hal ini terlihat ketika diberikan pembebanan maka dengan Pengontrolan daur tertutup ini bisa diperoleh kondisi yang lebih stabil ketika motor diberikan pembebanan yang berubah ubah besarnya seperti Grafik Diatas.

\section{KESIMPULAN}

1. Arus Starting pada motor Motor Listrik U.S. Electric MotorType Dripproof, $5 \mathrm{HP}, 240 \mathrm{~V}$, 18.3 A dengan DOL sebesar 1370 A dan kecepatan motor $2991 \mathrm{rpm}$

2. Pengendalian Motor DC kendali Jangkar dengan Pengaturan Tegangan Jangkar akan menurunkan Arus start menjadi 153,4 A dan kecepatan putar 2515,3 rpm

3. Pengendalian Motor DC kendali jangkar dengan Pengaturan Tahanan Seri menurunkan arus start menjadi 182,96 A dan kecepatan putar 2507 Rpm

4. Pada pembebanan Motor dengan Pengendali Daur terbuka ( Pengaturan Tegangan dan Pengaturan Tahanan Seri ) perubahan beban akan merubah kecepatan putar dan arus jangkar cukup besar pada pengaturan tegangan , namun pada pengendalian dengan Daur tertutup perubahan pembebanan tidak merubah arus jangkar dan kecepatan putar motor secara signifikan.

\section{DAFTAR PUSTAKA}

Amri, Irman, 2008, tugas $1 \sim 4$ PPML, PPS Unhas, Makassar.

Amri, Irman, 2008, catatan kuliah PPML, PPS Unhas Makassar.

Kadir, Abdul, Prof. Ir.,1991. Pengantar Teknik Tenaga Listrik., LP3ES, Jakarta.

Ogata,K. 1993.”Teknik Kontrol Otomatik : Sistem Pengaturan" Aliha Bahasa Insyinyur Edi Leksono, Jakarta

Stephanus A.A,Sentosa S.J.,Augusta SB. September 2002 ."Studi Penggunaan Permanen Magnet Servo Motor Tegangan 460 V DC, 1850 Rpm Pada Mesin Potong Karton”. Jurnal Teknik Elektro Vol. 2, No. 2,: 98 - 104, UKP, Jakarta. 